\title{
Mediating Effects of Depression on Relationships between Nutritional Status and Quality of Life among Older Adults: A Cross-Sectional Study
}

\author{
Nho, Ju-Hee ${ }^{1} \cdot$ Kim, Eun $\mathrm{Jin}^{2}$ \\ ${ }^{1}$ Associate Professor, College of Nursing, Jeonbuk Research Institute of Nursing Science, Jeonbuk National University, Jeonju, Korea \\ ${ }^{2}$ Graduate Student, College of Nursing, Jeonbuk National University, Jeonju, Korea
}

\begin{abstract}
Purpose: Nutritional status and depression are major factors that affect older adults' quality of life (QoL). This study aimed to examine the mediating effects of depression on the relationship between nutritional status and physical and mental QoL in older adults and to provide a foundation for developing an effective nursing intervention program to improve QoL. Methods: This study was a cross-sectional, correlational study. A convenience sample of 154 older adults was recruited from J Province, South Korea, between December 2019 and August 2020. Data were analyzed using PROCESS macro with a 95\% bias-corrected bootstrap confidence interval for the SPSS/WIN 25.0 program. Results: QoL positively correlated with nutritional status and negatively correlated with depression. After controlling for general covariates, depression partially mediated the relationship between nutritional status and QoL in older adults (physical QoL [Effect $=0.41,95 \% \mathrm{Cl}=0.08 \sim 0.81$ ], mental QoL [Effect $=0.38,95 \% \mathrm{Cl}=0.04 \sim$ 0.79]). Conclusion: Health promotion strategies are needed for older adults with poor nutritional status and high levels of depression. Additionally, nutritional status and depression in older adults affect QoL, with depression affecting QoL through nutritional status as a mediator. Therefore, interventions to improve the nutritional status and reduce depression among older adults must be developed and implemented.
\end{abstract}

Key Words: Aged; Depression; Malnutrition; Quality of life

\section{INTRODUCTION}

The older adult population aged 65 and older accounted for $15.7 \%$ of the population in 2020 , and will continue to increase, reaching $20.3 \%$ by 2025 in Korea [1]. Since the population of older adults is predicted to reach $43.9 \%$ by 2060, their quality of life (QoL) is an important social issue [1]. QoL is an important indicator of health for older adults, with more than half of the older adults worldwide reporting poor QoL [2], and the QoL of older adults in Korea has been reported to be relatively low compared to other countries [3].

Malnutrition among older adults deteriorates their health and reduces their QoL [4]. The rate of skipping breakfast in Korea is $8.2 \%$ for men and $11.9 \%$ for women [5]. Nutrient deficiency is a common and serious health problem among older adults; most older adults in Korea have malnutrition, the energy intake is only $56.7 \%$ of the estimated energy requirement, and most of the nutritional intake status does not meet the standards for Koreans; thus, it is necessary to improve nutrition management [6].

Depression is a common psychological problem and the leading cause of disability among older adults [7]. In a large cohort study $(1,168$ people aged $\geq 60), 26.1 \%$ of older adults from various countries reported that they suffered from depression [8]. In Korea, in a study targeting older adults (2,076 people aged $\geq 65$ years), the prevalence of mild and severe cases of depression was $34.8 \%$ [9], and in a long-term depressive trajectory study $(3,561$ people $\geq 65$ years old), it was reported that most older adults had persistent depressive symptoms [10]. Depression in older people has been reported as one of the major factors affecting QoL in both the East and West [8]. It has been found that providing regular screening to recognize

\footnotetext{
Corresponding author: Nho, Ju-Hee https://orcid.org/0000-0002-5260-5605

College of Nursing, Jeonbuk National University, 567 Baekje-daero, Deokjin-gu, Jeonju 54896, Korea.

Tel: +82-63-270-3108, Fax: +82-63-270-3127, E-mail: jhnho@jbnu.ac.kr
}

Received: Jan 4, 2022 / Revised: Feb 3, 2022 / Accepted: Feb 11, 2022

This is an open access article distributed under the terms of the Creative Commons Attribution Non-Commercial License (http://creativecommons.org/licenses/ by-nc/3.0), which permits unrestricted non-commercial use, distribution, and reproduction in any medium, provided the original work is properly cited. 
early depression in older adults is crucial [2]. Moreover, an accurate evaluation of depression among older adults and interventions to reduce depression are needed.

Higher nutritional status is believed to indicate better QoL in older adults, whereas lower depression might signify higher QoL [5]. However, there are insufficient studies to determine whether depression has a mediating effect on nutritional status and QoL in older adults. This research would enable an understanding of how the relationship between variables provides basic data for improving the QoL of older people. Depression had a significant indirect effect on QoL through nutritional status, and depression mediated $4.8 \sim 6.0 \%$ of the total effect of nutritional status on QoL $[4,11]$. In addition, good nutritional status not only improves QoL, but also has a positive effect on depression [4]. Accordingly, depression appeared to play a mediating role in the relationship between nutritional status and QoL. However, the previous study had a limitation in that the older people who visited the hospital were participants [4], thus, it is necessary to identify the mediating effect of depression on the relationship between nutritional status and QoL in the community-dwelling older adults. The mediating effect is important in practice because it provides information that elucidates the mechanisms of how the variables are related [12]. Therefore, as a strategy to improve the QoL of older people, the mediating effects of depression on nutritional status and QoL were investigated.

The purpose of this study was to identify the nutritional status, depression, and QoL of older adults, and to examine the mediating effect of depression on the relationship between nutritional status and QoL. The specific research objectives were as follows: i) determine the nutritional status, depression, and QoL of older adults, ii) identify the relationship between QOL and the characteristics of the participant, and iii) examine the mediating effect of depression on nutritional status and QoL.

\section{METHODS}

\section{Research Design}

This study used a cross-sectional correlational design to investigate the mediating effect of depression on the relationship between nutritional status and QoL among older adults.

\section{Setting and Samples}

Between December 2019 and August 2020, participants were recruited through convenience sampling from 16 institutions that agreed to participate (e.g., centers, older adult citizen centers, welfare centers, temples, and churches). Older adults were defined as those aged 65 years or older and further categorized as young-old ( $<75$ years) and old-old ( $\geq 75$ years) [13]. The inclusion criteria were as follows: i) age $\geq 65$ years, ii) understands the study's purpose and communicates in Korean, and iii) completes a consent form to participate in the study. The exclusion criteria were as follows: i) cognitive disabilities who had difficulty communicating and ii) taking medication after being diagnosed by a doctor for depression or anxiety.

After obtaining the consent of the institutions' heads, data were collected by four trained research assistants using structured questionnaires. For participants who did not bring glasses or could not read, the research assistants read the questionnaire verbatim and helped participants complete it, thereby ensuring the reliability of data collection.

As for the sample size, the multiple regression analysis with a significance level of .05 , power of .8 , and effect size of 0.15 median based on previous study [14] was determined using G*Power 3.1.9.7 (Universität Düsseldorf, Düsseldorf, Germany). When 12 predictors (gender, age, marital status, education, monthly income, residence, religion, occupation, living type, subjective health status, nutritional status, and depression) were input, 127 participants were requested. Questionnaires were distributed to 170 people considering the dropout rate $(20 \sim 30 \%)$, and data from $161(94.7 \%)$ people were analyzed after excluding incomplete data: $50 \%$ or more blank $(\mathrm{n}=7)$, and participants under 65 years old $(n=2)$.

\section{Measurements}

\section{1) Nutritional status}

The nutritional status of older adults was measured using a 17-item simple nutritional questionnaire developed for older adults, including factors such as fruit/milk food intake, eating behavior, eating pattern, appetite, age, household type, pocket money, education, and related diseases [16]. Of the 17 questions, 6 were out of two points and 11 were out of one point, with a total score range of $0 \sim 23$. Higher scores indicate a lower nutritional risk. Scores were classified as: $0 \sim 11$, high-risk for malnutrition; 12 16, moderate risk; and 17 23, low-risk. At the time of development, the sensitivity, specificity, and positive predictive value were $75.6 \%, 100 \%$, and $100 \%$, respectively [15], and Cronbach's $\alpha$ in this study was .72 . 


\section{2) Depression (Subscale of the DASS-21)}

Depression was assessed using the Depression, Anxiety, and Stress Scale (DASS-21) [16], which measures depressive anxiety and stress and consists of three subscales. It consists of a Likert scale ranging from zero to three. This study used a depression subscale containing seven items of the DASS-21, ranging from 0 to 21 , with higher scores indicating higher levels of depression. The validity and reliability of the Korean version of the DASS-21 has been well demonstrated [17]. At the time of development, Cronbach's $\alpha$ was .95 [16], and was .86 in this study.

\section{3) QoL (Short Form 12, SF-12)}

QoL was measured using the SF-12, the Medical Outcome Study Short Form-12 (MOS SF-12), which has been validated was verified in Korean by Quality Metric Incorporated [18]. SF-12 is an abbreviation of SF-36 and comprises 12 items in eight areas. The Physical Component Score (PCS) consisted of general health, physical function, physical role restrictions, and physical pain. The Mental Component Score (MCS) consisted of mental health, emotional roles, social function, and vitality. This tool is scored using the Health Outcomes Scoring Software 5.0, with scores ranging from 0 to 100 . Higher scores indicate higher QoL. At the time of tool development, Cronbach's $\alpha$ values were .67 for the PCS, and .70 for MCS [18]. In this study, the Cronbach's $\alpha$ values were .83 for PCS and .78 for MCS.

\section{4) Statistical analysis}

The collected data were statistically analyzed using SPSS version 25.0 (IBM Corp. Armonk, NY, USA). Descriptive statistics were used to analyze participants' general characteristics, nutritional status, depression, and QoL. The relationships between participants' general characteristics and QoL were identified by an independent t-test, $x^{2}$ test, and one-way ANOVA. Pearson's correlation coefficient was used for correlation between variables. To identify the mediating effect of depression, we used the PROCESS macro version 3.5.3, analyzed through bootstrapping (model 4, number of samplings: 5,000 ) to test the significance of mediating effects. The size of the mediating effect was estimated by checking the proportion of mediation (PM) between the indirect and total effects.

\section{5) Ethical considerations}

The study was approved by the Institutional Review Board of Jeonbuk National University (2019-10-016-003) where the authors are affiliated. In accordance with the
Helsinki Declaration, voluntary written consent was obtained after explaining the privacy guarantee, research purpose, content, anonymity, and the possibility of opting out.

\section{RESULTS}

\section{General Characteristics and the Levels of QoL according to General Characteristics}

Of the 154 participants, $86(55.8 \%)$ were female, the mean age was $76.8 \pm 6.5$ years, and the older adults aged 75 years and above accounted for the majority at 93 (60.4\%). The levels of PCS showed statistically significant differences by the general characteristics such as gender, age, marital status, education, occupation, living type, and subjective health $(p=.002 \sim<.001)$. The levels of MCS showed statistically significant differences by gender, education, occupation, and subjective health status $(p=.029$ .007) (Table 1)

\section{Nutritional Status, Depression and QoL}

Regarding nutritional status, $39.0 \%$ of the participants were classified into a high-risk group and 37\% into a moderate-risk group. The mean score of depression was 5.12 \pm 4.29 ; PCS and MCS were $63.43 \pm 14.07$ and $66.21 \pm$ 13.65 , respectively. The major variables were found to be normally distributed (Table 2).

\section{Correlation between QoL, Nutritional Status, and Depression}

The PCS showed a positive correlation with nutritional status $(\mathrm{r}=.54, p<.001)$ and a negative correlation with depression $(\mathrm{r}=-.56, p<.001)$. Similarly, the MCS showed a positive correlation with nutrition $(\mathrm{r}=.41, p<.001)$ and a negative correlation with depression $(\mathrm{r}=-.55, p<.001)$ (Table 3).

\section{Mediating Effect of Depression by Bootstrapping}

Variables significantly related to the PCS level (gender, age, marital status, education, occupation, living type, and subjective health status) were controlled as covariates. When depression was used as the dependent variable and nutritional status as the predictor variable, there was a significant negative relationship $(a=-0.30, p=.007)$. When nutritional status and depression were analyzed as predictors with PCS as the dependent variable, there was a 
Table 1. Quality of Life according to General Characteristics

$(N=154)$

\begin{tabular}{|c|c|c|c|c|c|c|}
\hline \multirow{3}{*}{ Characteristics } & \multirow{3}{*}{ Categories } & \multirow{3}{*}{$\begin{array}{l}\mathrm{n}(\%) \text { or } \\
\mathrm{M} \pm \mathrm{SD}\end{array}$} & \multicolumn{4}{|c|}{ QoL } \\
\hline & & & \multicolumn{2}{|c|}{ PCS } & \multicolumn{2}{|c|}{ MCS } \\
\hline & & & $\mathrm{M} \pm \mathrm{SD}$ & t or $\mathrm{F}(p)$ & $M \pm S D$ & t or $\mathrm{F}(p)$ \\
\hline Gender & $\begin{array}{l}\text { Male } \\
\text { female }\end{array}$ & $\begin{array}{l}68(44.2) \\
86(55.8)\end{array}$ & $\begin{array}{l}68.82 \pm 12.45 \\
59.17 \pm 13.88\end{array}$ & $\begin{array}{c}4.48 \\
(<.001)\end{array}$ & $\begin{array}{l}69.36 \pm 12.54 \\
63.72 \pm 14.03\end{array}$ & $\begin{array}{c}2.60 \\
(.010)\end{array}$ \\
\hline $\begin{array}{l}\text { Age (year) } \\
\text { (Range:65 89) }\end{array}$ & $\begin{array}{l}65 \sim 74 \\
\geq 75\end{array}$ & $\begin{array}{r}61(39.6) \\
93(60.4) \\
76.8 \pm 6.5\end{array}$ & $\begin{array}{l}68.52 \pm 12.54 \\
60.09 \pm 14.08\end{array}$ & $\begin{array}{c}3.79 \\
(<.001)\end{array}$ & $\begin{array}{l}68.14 \pm 13.52 \\
64.95 \pm 13.65\end{array}$ & $\begin{array}{c}1.43 \\
(.156)\end{array}$ \\
\hline Marital status & $\begin{array}{l}\text { Married } \\
\text { Others }\end{array}$ & $\begin{array}{l}89(57.8) \\
65(42.2)\end{array}$ & $\begin{array}{l}66.61 \pm 13.75 \\
59.08 \pm 13.41\end{array}$ & $\begin{array}{c}3.39 \\
(.001)\end{array}$ & $\begin{array}{l}67.38 \pm 13.12 \\
64.62 \pm 14.28\end{array}$ & $\begin{array}{l}1.24 \\
(.216)\end{array}$ \\
\hline Education & $\begin{array}{l}\leq \text { Elementary school }^{\mathrm{a}} \\
\text { Middle \& high school }^{\mathrm{b}} \\
\geq \text { University }^{\mathrm{c}}\end{array}$ & $\begin{array}{l}69(44.8) \\
61(39.6) \\
24(15.6)\end{array}$ & $\begin{array}{c}56.81 \pm 13.86 \\
66.93 \pm 12.23 \\
73.57 \pm 9.39\end{array}$ & $\begin{array}{c}19.58 \\
(<.001) \\
\mathrm{b}, \mathrm{c}>\mathrm{a}^{\dagger}\end{array}$ & $\begin{array}{l}63.57 \pm 14.09 \\
66.94 \pm 12.73 \\
71.94 \pm 13.15\end{array}$ & $\begin{array}{c}3.61 \\
(.029) \\
c>a, b^{\dagger}\end{array}$ \\
\hline $\begin{array}{l}\text { Monthly income } \\
(10,000 \text { won }) \\
(n=153)\end{array}$ & $\begin{array}{l}<200 \\
200 \sim 399 \\
\geq 400\end{array}$ & $\begin{array}{c}102(66.7) \\
41(26.6) \\
10(6.5)\end{array}$ & $\begin{array}{l}62.16 \pm 13.33 \\
65.16 \pm 14.85 \\
68.86 \pm 17.99\end{array}$ & $\begin{array}{c}1.47 \\
(.233)\end{array}$ & $\begin{array}{l}65.42 \pm 13.14 \\
67.07 \pm 14.57 \\
71.67 \pm 15.17\end{array}$ & $\begin{array}{l}1.05 \\
(.354)\end{array}$ \\
\hline Residence & $\begin{array}{l}\text { Urban } \\
\text { Rural }\end{array}$ & $\begin{array}{l}89(57.8) \\
65(42.2)\end{array}$ & $\begin{array}{l}62.28 \pm 14.40 \\
65.01 \pm 13.56\end{array}$ & $\begin{array}{l}-1.19 \\
(.235)\end{array}$ & $\begin{array}{l}64.53 \pm 13.53 \\
68.51 \pm 13.57\end{array}$ & $\begin{array}{l}-1.80 \\
(.074)\end{array}$ \\
\hline Religion & $\begin{array}{l}\text { Yes } \\
\text { No }\end{array}$ & $\begin{array}{r}111(72.1) \\
43(27.9)\end{array}$ & $\begin{array}{l}63.01 \pm 13.32 \\
64.52 \pm 15.97\end{array}$ & $\begin{array}{l}-0.60 \\
(.553)\end{array}$ & $\begin{array}{l}65.92 \pm 13.08 \\
66.98 \pm 15.15\end{array}$ & $\begin{array}{l}-0.43 \\
(.667)\end{array}$ \\
\hline Occupation & $\begin{array}{l}\text { Yes } \\
\text { No }\end{array}$ & $\begin{array}{r}32(20.8) \\
122(79.2)\end{array}$ & $\begin{array}{l}70.36 \pm 10.71 \\
61.62 \pm 14.32\end{array}$ & $\begin{array}{c}3.22 \\
(.002)\end{array}$ & $\begin{array}{l}71.04 \pm 13.48 \\
64.95 \pm 13.46\end{array}$ & $\begin{array}{c}2.28 \\
(.024)\end{array}$ \\
\hline Living type & $\begin{array}{l}\text { Alone }^{\mathrm{a}} \\
\text { With spouse }^{\mathrm{b}} \\
\text { With family } \\
\text { Facility residence }^{\mathrm{d}}\end{array}$ & $\begin{array}{c}49(31.8) \\
78(50.6) \\
23(14.9) \\
4(2.6)\end{array}$ & $\begin{array}{l}59.59 \pm 12.90 \\
67.00 \pm 13.83 \\
59.88 \pm 14.30 \\
61.43 \pm 18.88\end{array}$ & $\begin{array}{c}3.57 \\
(.016) \\
\mathrm{b}>\mathrm{d}>\mathrm{c}>\mathrm{a}^{\dagger}\end{array}$ & $\begin{array}{l}64.42 \pm 15.04 \\
67.56 \pm 12.87 \\
64.20 \pm 13.19 \\
73.33 \pm 12.47\end{array}$ & $\begin{array}{c}1.07 \\
(.365)\end{array}$ \\
\hline $\begin{array}{l}\text { Subjective health } \\
\text { status }\end{array}$ & $\begin{array}{l}\text { Healthy } \\
\text { Not healthy }\end{array}$ & $\begin{array}{l}80(51.9) \\
74(48.1)\end{array}$ & $\begin{array}{l}68.36 \pm 13.91 \\
58.11 \pm 12.25\end{array}$ & $\begin{array}{c}4.84 \\
(<.001)\end{array}$ & $\begin{array}{l}69.04 \pm 12.92 \\
63.15 \pm 13.87\end{array}$ & $\begin{array}{c}2.73 \\
(.007)\end{array}$ \\
\hline
\end{tabular}

${ }^{\dagger}$ Scheffé test; M=Mean; MCS=Mental component score; PCS=Physical component score; QoL=Quality of life; SD=Standard deviation.

Table 2. Nutritional status, Depression, and Quality of life in Older Adults

$(N=154)$

\begin{tabular}{|c|c|c|c|c|c|c|}
\hline Variables & Categories & $\mathrm{M} \pm \mathrm{SD}$ or $\mathrm{n}(\%)$ & Min & Max & Skewness & Kurtosis \\
\hline Nutritional status & $\begin{array}{l}\text { Total } \\
\text { High risk } \\
\text { Moderate risk } \\
\text { Low risk }\end{array}$ & $\begin{array}{c}12.99 \pm 4.52 \\
60(39.0) \\
57(37.0) \\
37(24.0)\end{array}$ & 3 & 22 & -0.20 & -0.69 \\
\hline Depression & $\begin{array}{l}\text { Total } \\
\text { Yes }(\geq 7)\end{array}$ & $\begin{array}{c}5.12 \pm 4.29 \\
48(31.2)\end{array}$ & 0 & 21 & 1.11 & 1.67 \\
\hline QoL (PCS) & & $63.43 \pm 14.07$ & 31.43 & 97.14 & -0.38 & -0.25 \\
\hline QoL (MCS) & & $66.21 \pm 13.65$ & 23.33 & 100.00 & -0.04 & 0.06 \\
\hline
\end{tabular}

$\mathrm{M}=$ Mean; MCS=mental component score; $\mathrm{PCS}=$ physical component score; $\mathrm{QoL}=$ quality of life; $\mathrm{SD}=$ standard deviation.

significant negative relationship between depression and PCS $(b=-1.38, p<.001)$. The direct effect of nutrition on PCS was found to have a statistically significant positive relationship ( $c^{\prime}=0.76,95 \%$ confidence interval $\mathrm{CI}=0.24 \sim$ 1.28). The mediating effect of nutritional status on PCS through depression was also statistically significant [(a.b) $=0.41,95 \% \mathrm{CI}=0.08 \sim 0.81]$. Therefore, nutritional status had statistically significant direct and indirect effects on PCS. The effect size of these mediations was 0.41 (Table 4) (Figure 1). 
Table 3. Correlation among Nutritional status, Depression and Quality of Life

$(N=154)$

\begin{tabular}{|c|c|c|c|c|}
\hline \multirow{2}{*}{ Variables } & Nutritional status & Depression & QoL (PCS) & QoL (MCS) \\
\hline & $r(p)$ & $r(p)$ & $r(p)$ & $r(p)$ \\
\hline Nutritional status & 1 & & & \\
\hline Depression & $-.24(.003)$ & 1 & & \\
\hline QoL (PCS) & $.54(<.001)$ & $-.56(<.001)$ & 1 & \\
\hline QoL (MCS) & $.41(<.001)$ & $-.55(<.001)$ & $.60(<.001)$ & 1 \\
\hline
\end{tabular}

MCS=mental component score; PCS=physical component score; QoL=quality of life.

Table 4. Mediating Effect of Depression by Bootstrapping

\begin{tabular}{|c|c|c|c|c|c|c|c|c|c|}
\hline QoL & Effect & Variables & B & SE & $\mathrm{t}$ & $p$ & \multicolumn{2}{|c|}{$95 \% \mathrm{CI}$} & PM \\
\hline \multirow{5}{*}{ PCS } & Direct effect & $\mathrm{NU} \rightarrow \mathrm{PCS}\left(\mathrm{c}^{\prime}\right)$ & 0.76 & .26 & 2.88 & .005 & 0.24 & 1.28 & \multirow{5}{*}{.350} \\
\hline & Indirect effect & $\mathrm{NU} \rightarrow \mathrm{DEP}(\mathrm{a})$ & -0.30 & .11 & -2.73 & .007 & -0.52 & -0.08 & \\
\hline & Indirect effect & $\mathrm{DEP} \rightarrow \mathrm{PCS}(\mathrm{b})$ & -1.38 & .20 & -7.03 & $<.001$ & -1.76 & -0.99 & \\
\hline & Indirect effect & $\mathrm{NU} \rightarrow \mathrm{DEP} \rightarrow \mathrm{PCS}(\mathrm{ab})$ & 0.41 & .19 & & & 0.08 & 0.81 & \\
\hline & Total effect & $\left(c^{\prime}+a b\right)$ & 1.17 & .30 & 3.94 & $<.001$ & 0.59 & 1.76 & \\
\hline \multirow{5}{*}{ MCS } & Direct effect & $\mathrm{NU} \rightarrow \mathrm{MCS}\left(\mathrm{c}^{\prime}\right)$ & 0.89 & .27 & 3.25 & .001 & 0.35 & 1.43 & \multirow{5}{*}{.299} \\
\hline & Indirect effect & $\mathrm{NU} \rightarrow \mathrm{DEP}(\mathrm{a})$ & -0.26 & .10 & -2.52 & .013 & -0.46 & -0.06 & \\
\hline & Indirect effect & $\mathrm{DEP} \rightarrow \mathrm{MCS}(\mathrm{b})$ & -1.47 & .22 & -6.76 & $<.001$ & -1.90 & -1.04 & \\
\hline & Indirect effect & $\mathrm{NU} \rightarrow \mathrm{DEP} \rightarrow \mathrm{MCS}(\mathrm{ab})$ & 0.38 & .19 & & & 0.04 & 0.79 & \\
\hline & Total effect & $\left(c^{\prime}+a b\right)$ & 1.27 & .31 & 4.14 & $<.001$ & 0.66 & 1.87 & \\
\hline
\end{tabular}

$\mathrm{CI}=$ Confidence interval; $\mathrm{DEP}=$ Depression; $\mathrm{MCS}=$ Mental component score; $\mathrm{NU}=$ Nutritional status; PM=Proportion mediated, ratio of the indirect effect to the total effect; PCS=Physical component score; QoL=Quality of life.

Covariate: PCS=gender, age, marital status, education, occupation, living type, subjective health status; MCS=gender, education, occupation, subjective health status.

Reference group: gender $=$ male, age $=\leq 75$, marital status $=$ others, education $=\geq$ university, occupation $=$ no, living type $=$ alone, subjective health status=not healthy.

Variables significantly related to MCS level (gender, education, occupation, and subjective health status) were controlled as covariates. When depression was used as a dependent variable and nutrition as the predictor variable, there was a statistically significant negative relationship $(\mathrm{a}=-0.26, p=.013)$. Analysis of MCS as a dependent variable and nutritional status and depression as predictors revealed a statistically significant negative relationship between depression and MCS $(b=-1.47, p<.001)$. The direct effect of nutritional status on MCS was found to have a statistically significant positive relationship (c'= $0.89,95 \% \mathrm{CI}=0.35 \sim 1.43$ ). The mediating effect of nutritional status on MCS through depression was also statistically significant $([a . b]=0.38,95 \% \mathrm{CI}=0.04 \sim 0.79)$. Therefore, the direct and indirect effects of nutritional status on MCS were significant; the effect size of these mediations was 0.38 (Table 4, Figure 1).

As the nutritional status measurement included demographic items such as age, marital status, and education level, as well as nutrition-related items, it may have affected the relationships between the variables due to multicollinearity. Accordingly, mediating effect was identified except for age, marital status, and education level. It was found that there was no difference from the results of this study (PCS: $[a . b]=0.31,95 \% \mathrm{CI}=0.07 \sim 0.58$; MCS: [a.b] $=0.32,95 \% \mathrm{CI}=0.05 \sim 0.65)$, it was confirmed that there was no distortion due to multicollinearity between concepts. Therefore, in this study, the mediating effect of depression on QoL was finally confirmed after controlling for covariates including age, marital status, and education.

\section{DISCUSSION}

In this study, it was confirmed that a better nutritional status of older adults was correlated with a higher quality of physical and mental life. This corresponds with a previous study [4] that reported a significant influence of nutritional status on QoL, while malnutrition and depres- 




$\mathrm{a}=$ regression coefficient of nutritional status predicting depression; $\mathrm{b}$ and $\mathrm{c}^{\prime}=$ regression coefficient of depression and nutritional status predicting QOL (PCS); c=total effect of nutritional status on QoL (PCS) while controlling for general characteristic covariates; $a \cdot b=$ indirect effect of nutrition on QoL (PCS) mediated by depression while controlling for general characteristic covariates; 95\% CI: 95\% bias-corrected bootstrap confidence interval; QoL (PCS): quality of life (physical component score).

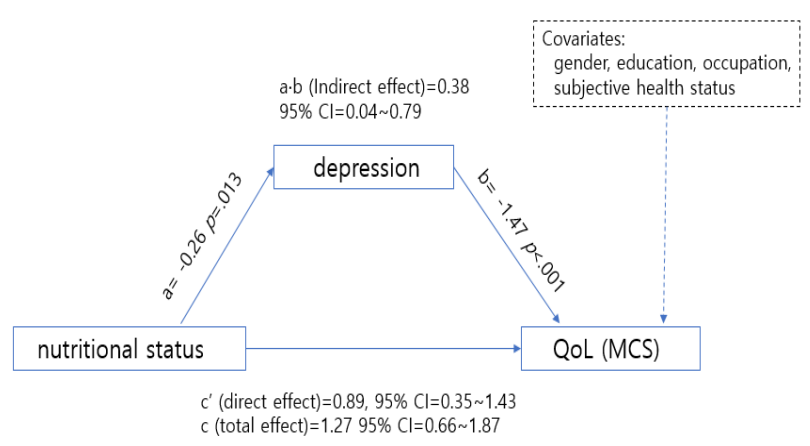

$\mathrm{a}=$ regression coefficient of nutritional status predicting depression; $\mathrm{b}$ and $\mathrm{c}^{\prime}=$ regression coefficient of depression and nutritional status predicting QOL (MCS); c=total effect of nutritional status on QoL (MCS) while controlling for general characteristic covariates; $a \cdot b=$ indirect effect of nutrition on QoL (MCS) mediated by depression while controlling for general characteristic covariates; 95\% CI: 95\% bias-corrected bootstrap confidence interval; QoL (MCS): quality of life (mental component score).

B. Mental component score.

\section{A. Physical component score.}

Figure 1. Statistical relationships in the mediation model for nutritional status, depression, and quality of life.

sion were found in most older adults. This study also found that approximately $76.0 \%$ of older adults belonged to the moderate-and high-risk groups in nutritional status, implying an urgent need to educate older adults regarding nutrition. The nutritional status of single-household older adults in South Korea was reported to indicate a high risk of malnutrition caused by undernourishment [19]. Since a good nutritional status is crucial to maintaining good health and QoL in older adults, healthcare providers should consider early intervention for nutrient deficiency or related risk factors among older adults [20]. For socially vulnerable older adults with low healthcare accessibility, active use of remote monitoring or visiting services such as visiting nurse management has been shown to significantly increase nutritional intake and improve nutritional status [21]. Therefore, education and policies are needed for nutritional management of vulnerable older people.

Nutritional health is essential for the QoL of older people. As depression is associated with nutritional status in older people, the implications of these findings on nutritional health are discussed [22]. As participants' depression showed a significant negative correlation with nutritional status in this study, it appears that depression prevention is necessary for older adults with high-risk nutritional status. These strategies can serve to develop guidelines such as regular monitoring, program development, and application for the prevention of depression and ef- fective nutritional improvement. As the role of nurses in nutrition has become increasingly important, they can provide an advantage in implementing nutrition-related interventions. Instead of providing older adults with theoretical knowledge, it is necessary to suggest specific methods that can be easily applied in daily life. Furthermore, healthcare providers should focus on nutritional management to ensure the supply of balanced nutrition to older adults at risk of malnutrition and to prevent malnutrition from causing frailty.

All the older adults in this study were identified as suffering from mild depression. In this study, the prevalence of depression (over moderate depression: $31 \%$ ) found in older adults in South Korea was $20.6 \%$, which is higher than that in middle-aged adults [23]. A possible reason for the higher level of depression in older adults is the close association with psychosocial factors, including vulnerability to stress, a high percentage of single-household adults, poor health status, and poverty [24]; in this study $31.7 \%$ of the older adults lived alone, $66.7 \%$ of those received less than 2 million won a month, and $48.1 \%$ experienced poor subjective health.

Based on the results of this study, management of depressive symptoms should be given top priority in enhancing the QoL of older adults. Thus, intervention programs to reduce the level of depression and enhance QoL in older adults should be developed and applied. In a study that provided home-based physical activity inter- 
ventions to 307 older adults for 6 months, depression and anxiety were reduced in participants [25], and it has been reported that a preventive lifestyle intervention performed for 4 months in 288 older adults in the England reduced depression and improved physiological and emotional relaxation as well as psychological well-being [26]. Thus, health care providers should promote the use of interventions to alleviate depression.

In this study, depression had a partial mediating effect on the relationship between nutritional status and physical and mental life of older adults; the nutritional status of older adults directly affects their physical and mental QoL, but can also affect the physical and mental QoL through depression. This is similar to the results of a previous study [4] which found that depression had mediating effect on the relationship between nutritional status and QoL. Depression affects the overall QoL in older adults and acts as a parameter in the relationship between QoL and nutritional status [14]. Therefore, depressive symptoms should be considered when measuring QoL in older adults and providing an active health promotion program.

A limitation of this study was that a cross-sectional design was used. Thus, it is difficult to identify depression, nutritional status, and QoL over time. Depression, nutritional status and QoL of the older adults change over time [27]. The QoL of the older adults is directly related to happiness for life, and is important to achieve a valuable old age as successful aging [28]. Therefore, longitudinal confirmation of the relationship between depression, nutritional status, and QoL of the older adults is also needed in the future. Therefore, the mediating effect of depression should be identified through a longitudinal study design. In addition, the generalizability of the results is limited, as the study was implemented in one region. Despite these limitations, the (partial) mediating mechanism of depression in the relationship between nutritional status and physical and mental QoL in older adults was identified. To improve the QoL of older adults, interventions that can reduce depression and improve their nutritional status are essential. Depression had a mediating effect on the relationship between nutritional status and QoL, suggesting that depression is crucial to older adults' QoL. Therefore, it would be helpful to incorporate depression management into community-based services for older adults.

\section{CONCLUSION}

Based on the results of this study, it is necessary to propose an intervention plan to reduce depression in older adults, along with nutritional improvement to improve their physical and mental QoL. In particular, a comprehensive approach and attention, including nutritional management and psychological support, is needed for the older adults living alone, low educational level, no occupation, and poor subjective health. Nutritional assessment and education that can improve nutritional status, and lifestyle interventions including physical activity that can reduce depression should be combined to improve QoL in older people.

\section{CONFLICTS OF INTEREST}

The authors declared no conflict of interest.

\section{AUTHORSHIP}

Author contribution: concept and design - NJ-H; Acquisition of subjects and/or data - NJ-H; Data analysis - NJ-H and KEJ; Interpretation - NJ-H and KEJ; Manuscript preparation - NJ-H and KEJ.

\section{FUNDING}

This work was supported by the National Research Foundation of Korea (NRF) grant funded by the Korea government (MSIT) (No. NRF-2018R1C1B6001070).

\section{ACKNOWLEDGEMENT}

None.

\section{REFERENCES}

1. Statistics Korea. 2020 Statistics of older adults [Internet]. Daejeon: Statistics Korea; 2020 Sep 28 [updated 2020 Sep 28; cited 2021 Jun 5]. Available from:

http://kostat.go.kr/portal/korea/kor_nw/1/1/index.board ?bmode $=$ read\&aSeq $=385322$

2. Juniarni L, Wulandari SS. The relationship between depression and the quality of life among elderly in nursing home. International Journal of Caring Sciences. 2020;13(3):2048-53.

3. Kim HY, Nho JH, Kim JY, Kim SR. Validity and reliability of the Korean version of the world health organization quality of life instrument-older adults module. Geriatric Nursing. 2021; 42(2):548-54. https:// doi.org/10.1016/j.gerinurse.2020.10.006

4. Ghimire S, Baral BK, Pokhrel BR, Pokhrel A, Acharya A, Amatya $\mathrm{D}$, et al. Depression, malnutrition, and health-related quality of life among Nepali older patients. BMC Geriatrics. 2018; 18(1):191. https://doi.org/10.1186/s12877-018-0881-5

5. Park SY, Shin JE. A study on the characteristics of health risk behavior in older adults with chronic joint pain using association analysis. Journal of Korean Gerontological Nursing. 2021; 23(2):107-16. https://doi.org/10.17079/jkgn.2021.23.2.107

6. Lee YY, Yang NR, Shin MJ, Lee KE, Yoo CH, Kim KR. The 
effect of a personalized nutrition intervention program on food security, health and nutritional status of low-income older adults in Seoul city. Journal of Nutrition and Health. 2020;53 (4):416-30. https://doi.org/10.4163/jnh.2020.53.4.416

7. Acciai F, Hardy M. Depression in later life: a closer look at the gender gap. Social Science Research. 2017;68:163-75. https://doi.org/10.1016/j.ssresearch.2017.08.003

8. Cao W, Guo C, Ping W, Tan Z, Guo Y, Zheng J. A community-based study of quality of life and depression among older adults. International Journal of Environmental Research and Public Health. 2016;13(7):693. https://doi.org/10.3390/ijerph13070693

9. Kim MI, Kim S, Eo Y. A study of depression in the elderly by individual and community effects. Health and Social Welfare Review. 2019;39:192-221. https://doi.org/10.15709/hswr.2019.39.2.192

10. Lee SH, Choi HH, Kim SH, Lee JU. Trajectories of depression and their associations with mortality in older people in Korea over 12 years. Korea Journal of Health Promotion. 2021;21(2): 45-55. https://doi.org/10.15384/kjhp.2021.21.2.45

11. Wang J, Xue J, Jiang Y, Zhu T, Chen S. Mediating effects of depressive symptoms on social support and quality of life among rural older Chinese. Health Qual Life Outcomes. 2020; 18(1):242. https:// doi.org/10.1186/s12955-020-01490-1

12. Hayes AF. Introduction to mediation, moderation, and conditional process analysis. A regression-based approach. 2nd ed. New York: Guilford Press; 2018. 692 p.

13. López J, Perez-Rojo G, Noriega C, Carretero I, Velasco C, Martinez-Huertas JA, et al. Psychological well-being among older adults during the COVID-19 outbreak: a comparative study of the young-old and the old-old adults. International Psychogeriatrics. 2020;32(11):1365-70. https://doi.org/10.1017/S1041610220000964

14. Chang YC, Yao G, Hu SC, Wang JD. Depression affects the scores of all facets of the WHOQOL-BREF and may mediate the effects of physical disability among community-dwelling older adults. PloS One. 2015;10(5):e0128356. https://doi.org/10.1371/journal.pone.0128356

15. Kim K, Hyun T, Lee J. Development of a simple screening test for identifying Korean elderly at risk undernutrition. Korean Journal of Community Nutrition. 2000;5(3):475-83.

16. Henry JD, Crawford JR. The short-form version of the Depression Anxiety Stress Scales (DASS-21): construct validity and normative data in a large non-clinical sample. British Journal of Clinical Psychology. 2005;44(2):227-39. https://doi.org/10.1348/014466505X29657

17. Cha ES. Cha Korean translation of the DASS21 [Internet]. Sydney: DASS; 2018 Jan 1 [updated 2018 Jan 1; cited 2019 Mar 10]. Available from: http://www2.psy.unsw.edu.au/dass

18. Ware Jr JE, Kosinski M, Keller SD. A 12-item short-form health survey: construction of scales and preliminary tests of reliabil- ity and validity. Medical Care. 1996;34(3):220-33. https://doi.org/10.1097/00005650-199603000-00003

19. Ham SW, Kim KH. Evaluation of the dietary quality and nutritional status of elderly people using the Nutrition Quotient for Elderly (NQ-E) in Seoul. Journal of Nutrition and Health. 2020;53(1):68-82. https://doi.org/10.4163/jnh.2020.53.1.68

20. Govindaraju T, Sahle BW, McCaffrey TA, McNeil JJ, Owen AJ. Dietary patterns and quality of life in older adults: a systematic review. Nutrients. 2018;10(8):971.

https://doi.org/10.3390/nu10080971

21. Van Doorn-van Atten MN, Haveman-Nies A, Pilichowski P, Roca R, De Vries JHM, De Groot CPGM. Telemonitoring to improve nutritional status in community-dwelling elderly: design and methods for process and effect evaluation of a nonrandomized controlled trial. BMC Geriatrics. 2018;18(1):284. https://doi.org/10.1186/s12877-018-0973-2

22. Bailly N, Maître I, Van Wymelbeke V. Relationships between nutritional status, depression and pleasure of eating in aging men and women. Archives of Gerontology and Geriatrics. 2015;61(3):330-6.

https://doi.org/10.1016/j.archger.2015.08.020

23. Lee MR, Jung SM, Bang H, Kim HS, Kim YB. The association between muscular strength and depression in Korean adults: a cross-sectional analysis of the sixth Korea National Health and Nutrition Examination Survey (KNHANES VI) 2014. BMC Public Health. 2018;18(1):1123.

https://doi.org/10.1186/s12889-018-6030-4

24. Pilania M, Yadav V, Bairwa M, Behera P, Gupta SD, Khurana H, et al. Prevalence of depression among the elderly (60 years and above) population in India, 1997-2016: a systematic review and meta-analysis. BMC Public Health. 2019;19(1):832.

https://doi.org/10.1186/s12889-019-7136-z

25. Aguiñaga S, Ehlers DK, Salerno EA, Fanning J, Motl RW, McAuley E. Home-based physical activity program improves depression and anxiety in older adults. Journal of Physical Activity and Health. 2018;15(9):692-6. https://doi.org/10.1123/jpah.2017-0390

26. Mountain G, Windle G, Hind D, Walters S, Keertharuth A, Chatters R, et al. A preventative lifestyle intervention for older adults (lifestyle matters): a randomized controlled trial. Age and Ageing. 2017;46(4):627-34.

https://doi.org/10.1093/ageing/afx021

27. Hohls JK, König HH, Quirke E, Hajek A. Anxiety, depression and quality of life-a systematic review of evidence from longitudinal observational studies. International Journal of Environmental Research \& Public Health. 2021;18(22):12022. https://doi.org/10.3390/ijerph182212022

28. Ju ES, Bang YS. A Systemic review of community-based programs for the quality of life of the elderly. Journal of the Korean Society of Integrative Medicine. 2021;9(2):173-81.

https://doi.org/10.15268/ksim.2021.9.2.173 